\section{Designação sexual em crianças intersexo: uma breve análise dos casos de "genitália ambígua"}

\author{
Sex assignment in intersex children: a brief analysis \\ of "ambiguous genitalia" cases
}

\begin{abstract}
Asignación sexual de niños intersexuales: un breve análisis de los casos de "genitales ambiguos"
\end{abstract}

Abstract

This article takes an ethical approach to briefly analyze current therapeutic guidelines in Brazil for cases diagnosed as "ambiguous genitalia" (one of the "disorders of sexual development", DSD) in intersex children. Except when there is clear risk to the infant's life, there is no medical or institutional consensus on the definition of intersex, DSD, or recommended treatment. Parents or guardians of these minors have the legal right to provide consent for genital surgical interventions. The irreversibility of some procedures calls attention to reports by some intersex adults who underwent such interventions during their childhood or adolescence and now fail to acknowledge the physical or psychosocial benefits that were originally claimed to justify them.

Disorders of Sex Development; Urogenital Abnormalities; Genitalia; Child
Anibal Guimarães 1

Heloísa Helena Barboza 2

\section{Resumo}

Sob uma perspectiva ética, este trabalho tem como objetivo oferecer uma breve análise das recomendações terapêuticas que, no Brasil, são atualmente propostas para o diagnóstico de intersexualidade em crianças. A vertente explorada é a da "genitália ambígua", considerada como uma das "anomalias da diferenciação sexual" (ADS). Salvo situações em que, de fato, existe risco de vida para os bebês diagnosticados como intersexo, não se verifica, na literatura internacional, consenso médico e institucional quanto à própria definição do que se denomina intersexo, nem tampouco quanto às recomendações terapêuticas propostas para o caso em questão. Cabe aos pais do incapaz, ou a seus responsáveis legais, a autorização para a realização de tais procedimentos. Dada a irreversibilidade que caracteriza alguns dos citados procedimentos, merecem atenção os relatos de pessoas intersexo que, em sua vida adulta, não reconhecem os benefícios físicos e psicossexuais que justificariam as intervenções sofridas em sua infância e adolescência.

Transtornos do Desenvolvimento Sexual; Anormalidades Urogenitais; Genitália; Criança 


\section{Introdução}

No Brasil, os procedimentos médico-cirúrgicos terapêuticos propostos para os casos de intersexualidade estão regulamentados pelo Conselho Federal de Medicina (CFM), pela Resolução no 1.664, de 2003 (R1664) 1. Neste texto, a intersexualidade, referida como "anomalias da diferenciação sexual” (ADS), é considerada uma "urgência biológica e social”. Destarte, a realização de cirurgias genitais em crianças recém-nascidas diagnosticadas como portadoras da chamada "genitália ambígua" é uma prática médica consagrada em nosso país. Contudo, à exceção dos poucos casos em que, de fato, existe risco de vida para esses bebês (como, por exemplo, os diversos tipos de hiperplasia congênita da suprarrenal), não se constata, na literatura científica internacional, consenso médico e institucional quanto à necessidade de realização imediata das referidas cirurgias. Nesse aspecto, cabe ressaltar que, para o caso em questão, não foram encontrados estudos de médicos brasileiros que proponham alternativas terapêuticas àquelas do CFM, ou narrativas de pessoas que, no Brasil, foram submetidas a tais procedimentos e se insurjam contra a sua realização.

O manejo clínico da intersexualidade é bastante complexo. Segundo Damiani \& GuerraJúnior 2 (p. 1014), "vários e controversos são os problemas que circundam o assunto". O atual debate em boa parte dos países ocidentais sugere, para além das controvérsias existentes no campo, falta de consenso entre seus diferentes atores no tocante à sua própria definição, não obstante as contribuições dos mais recentes estudos científicos. Por outro lado, como se procurará demonstrar, na clínica da intersexualidade, evidências científicas inquestionáveis deveriam subsidiar todas as etapas do processo de tomada de decisão.

À irreversibilidade que caracteriza as propostas cirúrgicas de intervenção na chamada genitália ambígua de crianças intersexo, soma-se a sua incapacidade legal e cognitiva para oferecer consentimento. Assim, cabe a terceiros - pais ou responsáveis informados pela equipe multidisciplinar que diagnostica as ADS - consentirem. Em consequência, a equipe multidisciplinar tem significativa responsabilidade em seu convencimento, na medida em que lhe cabe esclarecer o que for necessário à decisão dos pais, em sua maioria pessoas leigas e afligidas pela situação de seu/sua filho/a.

Nem sempre, porém, são apresentados argumentos convincentes aos pais. É o caso, por exemplo, que Machado ${ }^{3}$ acompanhou em uma maternidade no Rio Grande do Sul, Brasil, por ocasião da revelação aos pais do diagnóstico de genitália ambígua em seu filho recém-nascido. Embora, a olho nu, as "pequenas" dimensões daquele phallus remetessem à ideia de um pênis, para a equipe multidisciplinar, a "melhor solução" seria a sua remoção cirúrgica, seguida da criação de uma vagina. Na opinião de seus integrantes, essa seria a "única possibilidade de redução dos danos psíquicos a que aquela criança estaria exposta ao longo de sua vida". Mostrando-se surpreso com aquela "solução", o pai revelou à equipe que o seu próprio pênis era igualmente "diminuto", o que não representara qualquer empecilho para fecundar sua esposa. A avó paterna, também presente, disse que o pênis de seu marido também era "pequeno" e que ambos tiveram uma vida sexual bastante satisfatória. Segundo a bióloga Fausto-Sterling 4, a "urgência" em se remover o micropênis que, muitas vezes, é observado no momento do nascimento de um bebê pode se revelar uma decisão equivocada, porque irreversível, visto que esse mesmo pênis, sem sofrer qualquer intervenção médica, pode se desenvolver durante a puberdade, atingindo o que se considera como "tamanho normal".

Como ensina Dreger 5 , até meados da década de 1950, o modelo proposto de intervenção médico-cirúrgica para a designação de gênero em crianças portadoras da chamada genitália ambígua estava baseado na predominância das gônadas. A observação da anatomia interna do sujeito era crucial para a atribuição de seu "sexo", sendo de menor relevância a sua aparência genital. Contudo, ao que parece, esse modelo não era capaz de explicar determinados "desajustes" verificados entre o papel de gênero, identidade sexual e as redesignações de sexo realizadas em crianças e adolescentes assim diagnosticadas.

Nos anos imediatamente seguintes à 2a Guerra Mundial, o governo dos Estados Unidos, preocupado com a necessária retomada internacional do crescimento econômico e as possíveis repercussões que os crescentes movimentos pela emancipação feminina e liberdades civis poderiam acarretar à estabilidade social mundial de maneira geral, ofereceu enormes incentivos às pesquisas científicas na área da sexualidade para melhor tentar compreender sua dinâmica e, quiçá, interferir em sua "lógica". Inúmeros centros de pesquisa em todo o país foram criados e receberam maciços investimentos federais. Questões como a retomada da estabilidade dos papéis sexuais e de gênero de homens e mulheres, de certa forma esgarçados e/ou questionados durante o esforço de guerra, eram fonte de crescente preocupação da, então, mais poderosa nação militar e econômica que emergia do pós-guerra. 
Nesse ambiente, alguns pesquisadores se destacaram: Kinsey et al. 6, na Universidade de Indiana, dedicou-se à observação da sexualidade humana e, já em 1948, produziu Sexual Behavior in the Human Male, um estudo inovador sobre a sexualidade masculina; na Universidade Johns Hopkins, o psicólogo John Money aos poucos se tornou um dos principais estudiosos da época no tema da definição de papéis sexuais e de gênero. É seu um modelo que sugeria, em humanos, a plasticidade do gênero quando observadas determinadas regras. Dito de outro modo, acreditava Money que, em termos de desenvolvimento e fixação de uma dada identidade de gênero, a biologia teria revogadas suas leis quando lhe fosse oferecido um ambiente no qual o gênero cirurgicamente designado não fosse contrariado. Money, que vinha aos poucos testando suas hipóteses, formulou um modelo de abordagem para crianças que, por razões congênitas ou de traumatismos genitais, apresentavam deformações em sua genitália 7,8,9,10.

Para Fausto-Sterling 11, o espectro da homossexualidade perpassa toda a discussão em torno da questão da intersexualidade. A bióloga chama a atenção para o fato de que Money e seus colaboradores desenvolveram "o" modelo terapêutico para a intersexualidade em plena década de 1950, época em que a homossexualidade era definida como uma psicopatologia. Em outra obra 4 , a autora sugere que, nesse ambiente do pós-guerra, ao menos na sociedade norte-americana, a homossexualidade estava associada ao comunismo, sendo ambos considerados como uma ameaça à "segurança e integridade de crianças e mulheres, da família e da nação” (Bérubé 1990, apud Fausto-Sterling 4; p. 72).

Money parece ter encontrado em um caso específico as condições que, assim lhe pareceu, seriam ideais para testagem e confirmação "definitiva” de suas hipóteses. Para Fausto-Sterling 4 (p. 73), a impossibilidade ética de se manipular hormônios deliberadamente durante a fase de desenvolvimento fetal em humanos, "a qual é realizada impunemente em ratos e macacos", foi reelaborada e tornada natural por Money quando a natureza lhe ofereceu a possibilidade de realizar um experimento para estudo.

\section{A gênese do problema}

Curiosamente, a oportunidade de que necessitava Money surgiu quando lhe foi apresentado o caso de um bebê que não apresentava qualquer condição física que o fizesse ser reconhecido como intersexo. No ano de 1967, na cidade de Winnipeg (Canadá), o bebê Bruce Reimer - então com oito meses de idade - teve seu pênis carbonizado após ser submetido à circuncisão em um hospital público. Desorientada com o acontecimento, sua família foi aconselhada a procurar John Money, psicólogo do Hospital Universitário Johns Hopkins. Como parte das diversas intervenções médico-cirúrgicas por ele propostas, Bruce deveria ser submetido à cirurgia de "troca de sexo", de modo a se "fixar" seu novo gênero. Segundo Diamond \& Sigmundson 12, o "segredo" absoluto quanto aos procedimentos propostos e realizados em Bruce seria fundamental ao êxito de seu tratamento. De acordo com a estratégia desenhada por Money, a família de Bruce - agora registrado como Brenda Reimer - deveria também mudar para outra cidade, um lugar onde ninguém conhecesse a verdade.

Para poder comprovar sua teoria de que, com o tratamento prescrito, o gênero de Brenda havia sido ajustado, Money contava com a existência de Brian, o irmão gêmeo de Bruce, o qual não fora submetido à circuncisão. Criado como um menino, Bruce era o caso controle ideal para seu experimento. Como esclarece John Colapinto ${ }^{13}$, se os gêmeos de sexos opostos crescessem como "crianças ajustadas e felizes", seria inegável o domínio da cultura sobre a biologia na diferenciação dos sexos. Embora, desde o início, os fatos contrariassem as expectativas médicas e os esforços de Money, o caso - denominado John/ Joan - foi amplamente relatado nos anais da moderna Medicina como um estrondoso sucesso. Constituindo-se no novo paradigma, o modelo passou a nortear, em boa parte do planeta, as terapêuticas para os casos de intersexualidade em crianças recém-nascidas durante, pelo menos, os trinta anos seguintes. Afastava-se assim, em definitivo, a crença na "verdade" das gônadas. $\mathrm{Na}$ opinião de Fausto-Sterling 4 , rapidamente, o caso se tornou "o mais progressista, liberal e moderno” modelo até então proposto.

É certo que Brenda jamais se conformou com o papel de gênero que lhe foi imposto. Quando, aos 14 anos de idade, tomou conhecimento de seu histórico clínico - o qual, reitere-se, lhe havia sido insistentemente negado pelos demais médicos e, também, pela própria família - Brenda resolveu tentar, de todas as formas, reverter seu gênero. Adotando a partir de então o nome de David Reimer, ele se submeteu a inúmeras outras cirurgias genitais, bem como à administração de hormônios masculinos. Seus esforços, porém, não conseguiram atender à sua vontade e necessidade fundamental: restituir-lhe a condição masculina anterior. O sofrimento de David ante sua impotência para solucionar o problema acabou por levá-lo ao suicídio, em 2004, aos 37 anos de idade. Brian, seu irmão e caso-controle 
do experimento de Money, já havia se suicidado em 2002.

Não obstante todas as evidências contrárias, Money jamais admitiu haver forjado os dados apresentados à comunidade científica durante as três décadas que se seguiram a seu primeiro encontro com o bebê Bruce. Desde o início da divulgação de seus experimentos, apenas o médico Milton Diamond fora enfático ao apresentar, em público, suas desconfianças para aquilo que, embora amplamente alardeado, jamais havia sido objeto de refutação. Segundo Diamond, a teoria de Money, repleta de "furos evidentes" e "questões inconclusivas", não foi capaz de provocar questionamento por seus pares. Muito pelo contrário, Money era frequentemente saudado como um vitorioso, um pioneiro, alguém que havia contribuído decisivamente para estabelecer "verdades” sobre a formação dos papéis de gênero.

O encontro com Reimer serviu para Diamond ter finalmente confirmadas suas desconfianças. Apesar da resistência dos principais periódicos científicos àquela "bomba" que lhes era apresentada, em 1997 Diamond acabou conseguindo publicar o artigo em colaboração com Sigmundson 12 que revelava a verdade sobre o histórico clínico de Bruce/Brenda/David Reimer.

\section{A dificuldade conceitual e metodológica da intersexualidade}

A nomenclatura ADS, adotada pelo CFM no texto da R1664 1, veio a substituir o que, apontam Damiani \& Guerra-Júnior 2 , era até então referido na literatura inglesa como intersexo. Desenvolvida por Klebs 14, em 1876, o termo intersexo abrangia os diagnósticos de hermafroditismo verdadeiro e pseudo-hermafroditismo masculino ou feminino. A R1664 enumera as normas técnicas necessárias para o tratamento de pacientes diagnosticados como portadores das ADS. Sem repisar a sua conceituação, o texto apenas as relaciona. Assim, tem-se que "são consideradas [ADS] as situações clínicas conhecidas no meio médico como genitália ambígua, ambiguidade genital, intersexo, hermafroditismo verdadeiro, pseudo-hermafroditismo (masculino ou feminino), disgenesia gonadal, sexo reverso, entre outras" 1.

Observa-se que a denominação ADS se encontra em desacordo com a forma mais corrente utilizada na literatura científica internacional, tal como demonstrado a seguir. No documento emanado do Consenso de Chicago ${ }^{15}$, a categoria "intersexo" passou a ser denominada como "distúrbios do desenvolvimento sexual” (DDS; disorders of sexual development - DSD, em inglês). A anterioridade do texto da R1664 pode servir, em parte, para justificar a divergência. Dessa maneira, resulta imprecisa, ao menos em nosso país, a utilização do termo DDS, não obstante o seu uso consagrado na literatura científica internacional e em diferentes teses acadêmicas aqui produzidas desde 2005.

Se, por um lado, o consenso pela adoção de uma nova nomenclatura para o referido diagnóstico se deu a partir da reunião entre cinquenta especialistas das mais importantes entidades médicas norte-americanas e europeias, por outro fora do espaço médico e institucional, inexiste consenso para a sua utilização. De maneira resumida, tem-se que o movimento social de pessoas assim diagnosticadas se encontra dividido quanto à sua utilização. Por se recusar a acatar o que considera como a insistência na "medicalização" de sua conformação física, ensinam Dreger \& Herndon 16, uma parte continua a se autorreferir como pessoas "intersexo"; a outra parte aderiu à nova nomenclatura, acreditando que ela representa uma mudança de paradigma das propostas terapêuticas até então oferecidas, isto é, seu foco agora seria o paciente, e não mais o diagnóstico. Cabe destacar que expressiva parcela de pesquisadores acadêmicos, fora do ambiente da medicina, adota uma postura crítica e, em seus trabalhos científicos, mantém o uso dos termos "intersexo" e "intersexualidade".

Se, como afirma o National Institutes of Health (NIH) 17 dos Estados Unidos, "as anomalias congênitas dos órgãos sexuais” (p. 52) confrontam médicos com a necessidade de "atribuir sexo e realizar a reconstrução cirúrgica apropriada" (p. 52) em crianças intersexo, a mesma entidade reconhece que, atualmente, existe uma "crise no manejo clínico" (p. 53) dessas crianças. A American Academy of Pediatrics 18 (p. 139), por sua vez, em documento que propõe avaliar as terapias propostas para recém-nascidos portadores de genitália ambígua aponta que, antes de se estabelecerem os casos que, de fato, merecem investigação, "são necessários critérios clínicos bem definidos". Destacando "arbitrariedade" no estabelecimento de critérios para a conceituação dos diferentes DDS, a American Academy of Pediatrics oferece um exemplo significativo: "[dentro desse arcabouço teórico], mesmo o mais leve grau de hipospádias pode ser considerado como um exemplo de masculinização incompleta" 18 (p. 139). Ao se considerar a irreversibilidade das atuais propostas de intervenção cirúrgica, parece razoável imaginar que tal incerteza de critério diagnóstico pode resultar consequências físicas e psíquicas inimagináveis e indesejáveis para os sujeitos em questão.

Não obstante as atuais pesquisas terem como foco identificar mutações e outras variações 
genéticas que possam impactar no desenvolvimento do sistema reprodutivo de pessoas intersexo, autores como Houk \& Lee 19 (p. 28) sustentam que "permanece inadequada a compreensão científica das questões relacionadas aos DDS, [0 que acaba por comprometer o desenvolvimento] de linhas de cuidado [guidelines] sólidas para o enfrentamento de suas questões mais controversas. Persiste a necessidade de mais estudos, de modo a que médicos possam ter esclarecida uma resposta para a questão mais premente que lhes é apresentada: qual é a relação entre a decisão por eles tomada no tocante à realização de cirurgias genitais e redesignação sexual e a futura qualidade de vida e adaptação das pessoas intersexo nas quais tais procedimentos foram realizados". Para os autores, a proposta de revisão das controvérsias e questões atuais aponta, na maioria dos casos, o quão "pouco clara" continua a justificativa com que as atuais técnicas cirúrgicas de feminização e masculinização são utilizadas.

A American Psychological Association 20 reconhece a "discordância, muitas vezes, de especialistas quanto ao que pode ser considerado como uma condição de intersexualidade". Documento publicado em seu portal na Internet reitera, de maneira simples e objetiva, que é coletivamente denominada como "intersexualidade" a "variedade de condições que conduzem ao desenvolvimento atípico de características sexuais físicas. Essas condições podem incluir anormalidades dos genitais externos, dos órgãos reprodutivos internos, dos cromossomos sexuais, ou estarem relacionados aos chamados hormônios sexuais". Em outro exemplo de imprecisão na definição do que sejam os DDS, Reiner \& Gearhart 21 afirmam que extrofia da cloaca não é uma condição intersexo; para os autores, afalia e inadequação fálica seriam "anomalias estruturais". Documento emitido pelo NIH 17 lista extrofia da cloaca como uma das anomalias congênitas da diferenciação sexual.

A American Psychological Association 20 aponta que "em geral, não é medicamente necessária imediata realização de cirurgia [na genitália] de modo a torná-la reconhecidamente masculina ou feminina". Tal assertiva coloca em xeque a justificativa médica comumente utilizada, vale dizer, a realização da cirurgia seria conditio sine qua non para o ajuste psicossocial de crianças intersexo desde seus primeiros meses de idade, como forma de se assegurar, no futuro, uma adolescência e vida adulta "saudáveis", supostamente evitando-se o seu sofrimento e isolamento.

A psicóloga Suzanne Kessler 22 - uma das precursoras dos estudos em psicologia sobre a intersexualidade - sugere que, a despeito do imperativo médico-interventor que se apresenta aos casos de genitália ambígua, ao final, o alegado equilíbrio físico que justificaria a realização de intervenções médico-cirúrgicas tampouco é alcançado, uma vez que a sua manutenção é precária e somente se dá à custa de recorrentes e artificiais intervenções, "não se apagando" a ambiguidade em seus corpos. E mais. Os resultados do estudo de coorte com indivíduos geneticamente masculinos submetidos à cirurgia de redesignação sexual em sua infância apresentados por Reiner \& Gearhart 21 deixam em aberto as seguintes questões: em um modelo terapêutico que prescreve o segredo absoluto em relação à realização das cirurgias de troca de sexo, como reagirão no futuro os indivíduos que permaneceram no sexo feminino, depois de saber a verdade sobre seus históricos clínicos? Tal informação pode ser mantida em segredo?

Na literatura científica norte-americana da intersexualidade, a "retórica do vestiário" ("the locker-room" rethoric) é frequentemente sinalizada como um fator psicologicamente desestabilizador. Autores como Morland 23 questionam se a eventual exibição da genitália ambígua de algum de seus frequentadores naquele recinto, por sua inconformidade à norma, poderia mesmo suscitar comparações indesejáveis e, até mesmo, a humilhação pelas diferenças percebidas em sua aparência. Avançando seu argumento, diz Morland 24 que, ao contrário, a cirurgia genital pode acabar tornando "estranhas" anatomias que, de outra forma, passariam despercebidas. Neste aspecto, é considerado fundamental que, com seu pênis, o menino tenha a capacidade de urinar em pé. Spinola-Castro 25 (p. 57) corrobora esse raciocínio quando afirma que "o objetivo inicial da cirurgia é permitir que a criança esteja de acordo com o sexo e gênero designados e, também, permitir aos pais um benefício psicológico". Não deixa de ser curioso que, como destaca Haas 26 (p. 48), John Money, nas pesquisas que realizou ao longo da década de 1940 para a elaboração de sua tese de doutorado, tenha observado que "adultos intersexo que não foram submetidos à cirurgia de reconstrução genital apresentavam identidade de gênero comparável a outros adultos de sexo masculino e feminino". Lamentavelmente, ressalta Haas 26 (p. 49), "tais pesquisas jamais foram publicadas".

Dadas as controvérsias encontradas nesse campo, o NIH decidiu consultar algumas das mais importantes entidades profissionais da área da saúde nos Estados Unidos como forma de tentar promover maior consenso não apenas quanto à conceituação das ADS, mas também para delimitar suas propostas terapêuticas. Na exposição de motivos endereçada à Endocrine Society 27 pelo NIH em dezembro de 2013, por exemplo, 
é reconhecido que "pouco se sabe em relação aos efeitos no curto e longo prazo das atuais intervenções médicas ou psicossociais para os casos de DDS em crianças e em suas famílias nos diferentes períodos de seu desenvolvimento, as quais podem ter importantes implicações no tocante a se determinar a idade mais adequada [para a cirurgia] $e$, também, a natureza dos cuidados clínicos e psicológicos necessários. A multiplicidade de variáveis que afetam o desenvolvimento dessas crianças e a heterogeneidade de condições compreendidas pelos DDS representam desafios metodológicos para o estabelecimento de evidências científicas em relação às questões críticas observáveis nesse período, não apenas para elas, mas também para suas famílias e médicos envolvidos". O referido processo de consulta 27 se encerrou em fevereiro de 2014. Dada a hegemonia que tem a medicina norte-americana para a disseminação em todo o mundo do conhecimento científico ali produzido e, também, o aprimoramento de técnicas e tecnologias daí resultantes, é razoável que se dedique a máxima atenção aos desdobramentos dessa iniciativa do NIH.

Hurwitz ${ }^{28}$, em artigo que reconhece os enormes avanços alcançados no campo da cirurgia plástica feminizante para pacientes com ADS, é enfático em suas críticas. Reconhece o autor que "encontram-se agora disponíveis conhecimento e técnicas para a realização de genitoplastias bemcuidadas e bem-sucedidas, o que inclui a preservação de sensação no clitóris, a exteriorização da vagina, com técnicas capazes de minimizar as chances de estenose, tornando seu resultado cosmético tão natural quanto possível" 28 (p. 171). Contudo, ressalta Hurwitz 28 (p. 171), "falta padronização e rigor metodológico na apresentação de resultados convincentes para justificar as intervenções preconizadas".

Precisamente em relação aos estudos longitudinais, esclarece o autor que, "salvo quando comprovada a anatomia pré-operatória [dessas crianças], os resultados cirúrgicos apresentados são confusos" 28 (p. 171) . Para Hurwitz 28 (p. 171), "Deve-se igualmente relatar as diferentes [ADS] de maneira individual, e não agrupá-las [para relatar resultados supostamente favoráveis à tese pretendida]. Tabelas de classificação uniformes e descritivas são necessárias para se proceder à avaliação dos resultados anatômicos e funcionais alegados, bem como é [preocupante] a inexistência de questionários para a avaliação da autoimagem e do status psicossocial da pessoa intersexo. $\hat{E}$ essencial que, no longo prazo, seja feita em adultos a avaliação da globalidade das decisões tomadas, e também dos tratamentos e decisões tomadas. $E$ fundamental avaliar os resultados anatômicos e funcionais sob a perspectiva do paciente adulto".
As questões conceituais e metodológicas também repercutem diretamente no cotidiano da clínica da intersexualidade. O efetivo exercício das equipes multidisciplinares voltadas para o enfrentamento das diferentes questões que o diagnóstico de ADS em recém-nascidos suscita para os diversos atores envolvidos, tal como preconizada pelo CFM no texto de sua R1664 1, encontra determinados entraves já desde seu processo de formação. Para Moran \& Karkazis 29 (p. 1), tal fato representa "um importante dilema, com sérias repercussões para o futuro dos cuidados dos DDS", uma vez que "não se encontra disponível orientação capaz de preencher a lacuna existente entre [um dado] grupo de profissionais, afinados no tocante à compreensão das referidas questões, desejosos de melhorar o seu manejo, $e$ uma equipe multidisciplinar [com diferentes perspectivas para o problema]". Ao que parece, o NIH conhece o problema porque constata que "poucos profissionais na área de saúde mental detêm a expertise específica para participar no cuidado e na pesquisa clínica interdisciplinar" 17 (p. 53). Mutatis mutandis, os comitês de ética existentes nos diferentes centros de pesquisa clínica enfrentam o mesmo problema quando reúnem em torno das questões que lhes são submetidas membros com diferentes formações, perspectivas e crenças, sejam eles representantes de usuários, médicos, pesquisadores da área e de outros campos, quando não teólogos.

\section{Alguns fatos da clínica médica}

Embora tenha sido o psicólogo Milton Diamond o responsável por trazer à tona a verdade sobre o caso de David Reimer, é importante frisar que ele não foi o único profissional, à época, a desconfiar dos relatos ou do modelo elaborado por John Money. Sem alcançar o mesmo destaque, alguns outros estudiosos já o haviam desafiado. É o caso do psiquiatra Bernard Zuger 30 que, em 1970, conseguiu publicar um artigo relatando diversos estudos clínicos, nos quais adolescentes e adultos intersexo, rejeitando o sexo em que foram criados, insistiam em trocá-lo. Segundo Fausto-Sterling 4, Money ficou "furioso" com tal publicação; no entanto, no meio científico, foram pequenas as repercussões para a ousadia de Zuger.

Sugere o médico Timothy F. Murphy 31 que, pelos mais diferentes motivos, não é possível saber o número total de experimentos que, com base no modelo de Money, foram realizados em outras crianças, ao longo de pelo menos trinta anos. À medida que tais resultados não são divulgados, acredita Murphy, médicos continuam a afirmar que, em determinadas circunstâncias, 
"benefícios" maiores que "riscos" os autorizam a prosseguir em suas ações.

Entretanto, a julgar pelas nefastas consequências observadas em David Reimer, devem ser objeto de nossas mais sinceras preocupações as razões pelas quais, nos anos que se seguiram à divulgação inicial por Money \& Ehrhardt 10 do caso John/Joan, os editores dos principais periódicos científicos internacionais resistiram em publicar artigos que questionavam a falta de relatos de sua atualização. Tal atitude provavelmente prejudicou o debate que se tornara necessário. Talvez, com o aprofundamento da questão, o sofrimento de David Reimer pudesse ter sido abreviado e inúmeras outras cirurgias e terapêuticas em diferentes crianças poderiam ter sido objeto de reconsideração médica, caso se conseguisse furar o bloqueio dos periódicos científicos ao questionamento das ideias de Money.

Por outro lado, como mencionado abaixo, existem diferentes relatos de médicos que, isolada e independentemente de posicionamentos institucionais contrários, decidiram mudar substancialmente suas práticas clínicas após compreenderem que eram inconsistentes, ou insuficientes, as evidências científicas que sustentavam determinadas recomendações terapêuticas. Não menos importante para sua tomada de decisão foram as crescentes denúncias de pessoas intersexo, portadoras da chamada genitália ambígua, que haviam sido submetidas a diferentes cirurgias genitais. Elas relatavam que, contrariamente às justificativas médicas, os procedimentos não lhes proporcionaram bem-estar psicossocial e, dentre outros alegados danos, também causavam consideráveis prejuízos à sua sensibilidade genital. Por rejeitarem um modelo consagrado após intensa e extensa prática interventiva, parece prudente ouvir esses médicos.

É o caso de William G. Reiner, originalmente urologista-pediatra em Johns Hopkins. Sensível aos inauditos argumentos que Milton Diamond trazia para o debate desde que John Money alardeou o caso John/Joan Reiner, durante 98 meses, Reiner lançou-se a também investigar uma coorte de 16 crianças diagnosticadas com extrofia da cloaca. Todas as crianças eram geneticamente do sexo masculino. Dada a prevalência do modelo formulado por Money, 14 dessas crianças haviam sido submetidas à cirurgia de redesignação sexual e passaram a viver como meninas. Apenas duas delas não tiveram a autorização de seus pais para a realização da cirurgia e viviam como meninos. No artigo em que relata o referido estudo, Reiner \& Gearhart 21 (p. 334) apontam que o conceito da plasticidade de gênero em neonatos e a recomendação da adequada construção de sua genitália "eram especialmente importantes para médicos que tratavam de casos de indivíduos geneticamente masculinos que apresentassem afalia, uma vez que não era viável a construção de um pênis funcional".

Dentre os resultados mais surpreendentes encontrados pelos autores, pode-se destacar: dos 14 que foram submetidos inicialmente à cirurgia, oito se diziam homens; os dois que não tiveram a cirurgia autorizada por seus pais permaneciam como homens. Todos aqueles que passaram a viver como meninas relataram dificuldades para se integrar com colegas geneticamente femininas; os que se converteram ao sexo masculino relatam alguns poucos subsequentes problemas com as colegas geneticamente femininas. Em relação à sua integração com colegas geneticamente masculinos, todos os 16 relataram ter poucas dificuldades.

Reiner \& Gearhart 21 são enfáticos quando dizem que a eventual redesignação sexual em crianças geneticamente masculinas com diagnóstico de inadequação fálica pode complicar ainda mais condições neonatais que já se mostravam complexas. Para os autores 21 (p. 340), "intervenções clínicas para tais neonatos deveriam ser reconsideradas à luz desses resultados". É pertinente que se reitere que outros autores, como Imperato-McGinley et al. 32 e, também, Bin-Abbas et al. 33, já haviam apresentado estudos de casos clínicos com resultados que "pareciam refutar [a aplicação do paradigma proposto por Money] em crianças que apresentavam outros diagnósticos" 21 (p. 339). Cabe ressaltar que Reiner não mais atua como urologista-pediatra, tendo se voltado para a psiquiatria pediátrica.

O médico Timothy F. Murphy, em artigo que trata das questões éticas que emergem na pesquisa e prática clínica, analisa também algumas das consequências que o caso John/Joan teve na disseminação do modelo proposto por John Money ${ }^{31}$. Segundo Murphy 31 , não obstante o "silêncio científico" de que se revestiu Money quando teve comprovado o fracasso de seu experimento, o psicólogo insistia em citá-lo como evidência de suas hipóteses sobre a plasticidade do gênero.

Ao tentar problematizar o caso John/Joan, Murphy 31 imagina que a equipe liderada por Money teve como proposta "simplesmente oferecer uma nova forma de cuidado” (p. 142), ou seja, não procurava "responder, de maneira definitiva, questões sobre intervenções no gênero" (p. 142). Todavia, avança Murphy, "se médicos são livres para inovar no cuidado clínico, eles têm uma obrigação ética de acompanhar, de forma sistematizada, os resultados de suas inovações” (p. 142-3). Em resumo 31 (p. 143), a "liberdade clínica" de que trata Murphy não pode implicar 
negligência na proteção dos "direitos e bem-estar dos pacientes".

Em 2003, John Money finalmente rompeu seu silêncio após a divulgação por Milton Diamond da verdade sobre o caso John/Joan. Foram essas as suas palavras: "Nunca realizei uma circuncisão - cirurgia que classifico como mutiladora -, não realizo experimentos de amputação de genitais em bebês do sexo masculino de modo a criá-los como meninas. Não sou cirurgião. Não realizo cirurgias reconstrutoras. Não realizo cirurgias de redesignação sexual. Não prescrevo hormônios. Não exploro pacientes com propósito de ganhos financeiros ou acadêmicos. Não detenho poder tirânico sobre Johns Hopkins ou qualquer de seus médicos. Sou um psicopediatra e, na medida do possivel, meu trabalho é ajudar pessoas em crise" (Money, 2003, apud Murphy 31; p. 146). Na opinião de Murphy, embora não seja falso o que disse Money, é fato que coube a ele atuar como "arquiteto-chefe" do projeto desenvolvido em Bruce Reimer, e sua negação a posteriori da responsabilidade que lhe cabe "não é simplesmente crível”. Da mesma forma, prossegue Murphy, ficaremos "sem resposta" quando perguntamos se todas as demais pessoas que participaram das diversas etapas do processo experimentado em Bruce Reimer acreditaram que estavam agindo mesmo em seu melhor interesse 31 . Money faleceu em 2004

Para nosso propósito específico, é relevante conhecer uma importante reflexão que faz o médico Timothy F. Murphy a respeito de sua atuação profissional. Em 1994, por ocasião dos preparativos da Enciclopédia de Bioética, coubelhe incluir um verbete sobre gênero e transtorno de identidade de gênero ${ }^{34}$. Mas, para o autor 31 (p. 149), de todos os trabalhos escritos por ele realizados, esse é o que mais lamenta, uma vez que suas "conclusões dependeram de relatos científicos que se provaram infundados", visto que cerca de 15 anos antes de escrever o verbete, "David Reimer já havia dado fim à sua identidade feminina". Em resumo, Murphy diz que confiou em relatos científicos cujo autor, Money, já sabia serem incorretos, mas que, mesmo assim, "nada fez para se retratar". Como Murphy, muitos outros pesquisadores e médicos, que tampouco sabiam que aquele experimento provara ser "um espetacular fracasso", continuaram a endossar o modelo proposto por Money.

\section{Considerações finais}

As questões aqui levantadas apontam para a vastidão e complexidade das problemáticas da intersexualidade, em especial para aquelas relativas à genitália ambígua. À força do discurso médico hegemônico - que preconiza a urgência na correção de corpos "defeituosos" de modo a se prevenir "danos futuros" -, opõe-se a compreensão por diferentes campos de pertinência, como é o caso da biologia.

Também merece consideração médica o testemunho de pessoas que sofreram em seus próprios corpos as intervenções médico-cirúrgicas prescritas para definição sexual, como apontado nos estudos de Hegarty \& Chase 35, Holmes 36 Morland 37, Cabral 38, dentre outras. Todas revelam ter sofrido exatamente os mesmos danos que, por exemplo, a R1664 1 procura prevenir quando prescreve a intervenção: intenso sofrimento físico e psíquico, insensibilidade genital, desajuste social e baixa autoestima. Parece incontestável a sua legitimidade (ou de seus representantes) para, pelo menos, protestar pela interrupção/moratória das recomendações compulsórias para o tratamento dos casos de genitália ambígua em que, efetivamente, não exista risco de vida e severo comprometimento funcional. A corroborar a força de tais testemunhos, o relato de Hida Viloria 39 é significativo: diagnosticada, desde criança, como portadora de genitália ambígua, ela não sofreu qualquer intervenção médico-cirúrgica ao longo de sua vida. Segundo Viloria, isso teria lhe permitido formar uma crença positiva quanto a seu corpo e identidade 39

Por si só, posições tão díspares implicam a necessidade de questionar o discurso médico pró-intervenção, especialmente quando se consideram as críticas institucionais e de importantes pesquisadores. Tal reflexão se justifica em função da realização dessas intervenções irreversíveis que implicam sofrimento evitável, portanto, injustificável, ao menos nos casos de genitália ambígua.

Passados 11 anos de sua edição, acredita-se oportuno o reexame da R1664 pelo CFM. Tal decisão evidenciará sua preocupação não apenas com o bem-estar físico e psicossocial desses seres vulneráveis como, também, a observância ética da conduta de seus profissionais naquilo que preconiza o texto. 


\section{Resumen}

Con un enfoque ético, este artículo pretende ofrecer un breve análisis de las propuestas terapéuticas que, en la actualidad en Brasil, son recomendadas para niños diagnosticados por sus "genitales ambiguos" (uno de los "trastornos del desarrollo sexual", TDS). Salvo en los casos cuando existe un claro riesgo para la vida de los bebés, no hay consenso médico o institucional con respecto a la definición de la intersexualidad, TDS o terapéuticas recomendadas. La incapacidad legal y cognitiva de estos niños autoriza a sus padres o responsables legales la tarea de ofrecer consentimiento para estas medidas terapéuticas médicas no reversibles. A pesar de que la promesa médica para justificar las intervenciones quirúrgicas en estos niños es lograr resultados positivos, algunas narrativas de personas intersexuales adultas no las reconocen de esta forma. Para estas personas, el sufrimiento físico y psicosexual que ellos viven en el presente no justificaría las intervenciones quirúrgicas que ellos han sufrido en su niñez y su adolescencia.

Trastornos del Desarrollo Sexual; Anomalías

Urogenitales; Genitales; Niño

\section{Referências}

1. Conselho Federal de Medicina. Resolução no $1.664 / 2003$, de 12 de maio de 2003. Dispõe sobre as normas técnicas necessárias para o tratamento de pacientes portadores de anomalias de diferenciação sexual. Diário Oficial da União 2003; 13 mai.

2. Damiani D, Guerra-Júnior G. As novas definições e classificações dos estados intersexuais: o que o Consenso de Chicago contribui para o estado da arte? Arq Bras Endocrinol Metab 2007; 51:1013-7.

3. Machado PS. O sexo dos anjos: representações e práticas em torno do gerenciamento sociomédico e cotidiano da intersexualidade [Tese de Doutorado]. Porto Alegre: Programa de Pós-graduação em Antropologia Social, Instituto de Filosofia e Ciências Humanas; Universidade Federal do Rio Grande do Sul; 2008.

\section{Colaboradores}

A. Guimarães concebeu o estudo e o artigo, participou da revisão da literatura, da redação inicial do manuscrito e a aprovação final da versão a ser publicada. H. H. Barboza colaborou na concepção do estudo, na revisão da literatura, na redação e revisão crítica do manuscrito e na sua aprovação final.
4. Fausto-Sterling A. Sexing the body: gender politics and the construction of sexuality. New York: Basic Books; 2000.

5. Dreger AD. Hermaphrodites and the medical invention of sex. Cambridge: Harvard University Press; 1998.

6. Kinsey AC, Pomeroy WR, Martin CE. Sexual behavior in the human male. Philadelphia: W.B. Saunders/Bloomington: Indiana University Press; 1948.

7. Money J, Hampson JG, Hampson JL. An examination of some basic sexual concepts: the evidence of human hermaphroditism. Bull Johns Hopkins Hosp 1955; 97:301-19.

8. Money J. Sex hormones and other variables in human eroticism. In: Young WC, editor. Sex and internal secretions. 3rd Ed. Baltimore: Williams \& Wilkins; 1961. p. 1383-400. 
9. Money J. Cytogenetic and psychosexual incongruities with a note on space-form blindness. Am J Psychiatry 1963; 119:820-7.

10. Money J, Ehrhardt AA. Man and woman/boy and girl. Baltimore: Johns Hopkins University Press; 1972.

11. Fausto-Sterling A. The five sexes, revisited. The emerging recognition that people come in bewildering varieties is testing medical values and social norms. The Sciences 2000; 19-23.

12. Diamond M, Sigmundson HK. Sex reassignment at birth. Long-term review and clinical implications. Arch Pediatr Adolesc Med 1997; 151:298-304.

13. Colapinto J. Sexo trocado, a história real do menino criado como menina. Rio de Janeiro: Ediouro; 2001.

14. Klebs E. Handbuch der pathologischen anatomie. Berlin: August Hirschwald; 1876

15. Lee PA, Houk CP, Ahmed SF, Hughes IA; International Consensus Conference on Intersex organized by the Lawson Wilkins Pediatric Endocrine Society and the European Society for Paediatric Endocrinology. Consensus statement on management of intersex disorders pediatrics. International Consensus Conference on Intersex. Pediatrics 2006; 118:e488-500.

16. Dreger AD, Herndon AM. Progress and politics in the intersex rights movement: feminist theory in action. GLQ: A Journal of Lesbian and Gay Studies 2009; 15:199-224.

17. Department of Health and Human Services, National Institutes of Health, National Institute of Diabetes \& Digestive \& Kidney Diseases. Strategic plan for pediatric urology. NIDDK - Research Progress Report. Bethesda: National Institutes of Health, National Institute of Diabetes \& Digestive \& Kidney Diseases; 2006. (NIH Publication, 065879).

18. Evaluation of the newborn with developmental anomalies of the external genitalia. American Academy of Pediatrics. Committee on Genetics. Pediatrics 2000; 106(1 Pt 1):138-42.

19. Houk CP, Lee PA. Update on disorders of sex development. Curr Opin Endocrinol Diabetes Obes 2012; 19:28-32.

20. American Psychological Association. Individuals with intersex conditions. http://www.apa.org/top ics/lgbt/intersex.pdf (acessado em 21/Mar/2013).

21. Reiner WG, Gearhart JP. Discordant sexual identity in some genetic males with cloacal exstrophy assigned to female sex at birth. N Engl J Med 2004; 350:333-41.

22. Kessler SJ. Lessons from the intersexed. New Jersey: Rutgers University Press; 1998.

23. Morland I. Plastic man: intersex, humanism and the Reimer case. Subject Matters 2007; 3/4:81-98.

24. Morland I. What can queer theory do for intersex. GLQ: A Journal of Lesbian and Gay Studies 2009; 15:285-312.

25. Spinola-Castro AM. A importância dos aspectos éticos e psicológicos na abordagem do intersexo. Arq Bras Endocrinol Metab 2005; 49:46-59.
26. Haas K. Who will make room for the intersexed? Am J Law Med 2004; 30:41-68.

27. Endocrine Society. NIH requests society suggestions for DSD workshop. https://www.endocrine. org/membership/email-newsletters/endocrineinsider/2014/january-8-2014/nih-requests-soci ety-suggestions-for-dsd-workshop (acessado em $11 / \mathrm{Jan} / 2014)$

28. Hurwitz RS. Feminizing surgery for disorders of sex development: evolution, complications, and outcomes. Curr Urol Rep 2011; 12:166-72.

29. Moran ME, Karkazis K. Developing a multidisciplinary team for disorders of sex development: planning, implementation, and operation tools for care providers. Adv Urol 2012; 2012:604135.

30. Zuger B. Gender role determination: a critical review of the evidence from hermaphroditism. Psychosom Med 1970; 32:449-63.

31. Murphy TF. Experiments in gender: ethics at the boundaries of clinical practice and research. In: Sytsma SE, editor. Ethics and intersex. Dordrecht: Springer; 2006. p. 139-51.

32. Imperato-McGinley J, Peterson RE, Gautier T, Sturla E. Androgens and the evolution of male-gender identity among male pseudohermaphrodites with 5a-reductase deficiency. N Engl J Med 1979; 300:1233-7.

33. Bin-Abbas B, Conte FA, Grumbach MM, Kaplan SL. Congenital hypogonadotropic hypogonadism and micropenis: effect of testosterone treatment on adult penile size - why sex reversal is not indicated. J Pediatr 1999; 134:579-83.

34. Murphy TF. Gender and gender identity disorders. In: Reich WT, editor. Encyclopedia of bioethics. v. 2. New York: Macmillan; 1994. p. 943-8.

35. Hegarty P, Chase C. Intersex activism, feminism and psychology: opening a dialogue on theory, research and clinical practice. Fem Psychol 2000; 10:117-32

36. Holmes MML. The doctor will fix everything: intersexuality in contemporary culture [Doctoral Dissertation]. Montréal: The Humanities Doctoral Programme, Concordia University; 2000.

37. Morland ICF. Narrating intersex: on the ethical critique of the medical management of intersexuality, 1985-2005 [Doctoral Dissertation]. Egham: Royal Holloway, University of London; 2005.

38. Moreno M. La excepción y la regla. http://www. pagina12.com.ar/imprimir/diario/suplementos/ radar/9-1316-2004-03-21.html (acessado em 14/ Mar/2010).

39. Viloria H. Intersex and medical treatment. http:// oiiusa.org/treatment (acessado em 29/Nov/2011).

Recebido em 24/Set/2013

Versão final reapresentada em 22/Jan/2014

Aprovado em 18/Mar/2014 